\title{
A review of paediatric liver resections in Johannesburg: Experiences and preferred technique
}

J A Loveland, F Krog, P Beale

Background. Liver resections are widely performed in paediatric surgery. Many techniques exist to achieve vascular control, minimise bleeding and complete the parenchymal division.

Methods. We retrospectively reviewed all liver resections performed in the Department of Paediatric Surgery at our institution between January 2005 and June 2012. Data pertaining to basic demographics, indications for surgery, parenchymal transection techniques, morbidity, mortality and histology were collated.

Results. Twenty-one resections were performed in children aged 6 weeks - 11 years; 18 for malignant liver disease (including 9 hepatoblastomas), and 3 for benign disease. We describe 1 perioperative mortality secondary to torsion of the liver remnant, and no surgical morbidity. Three cases underwent total hepatic vascular exclusion with sharp parenchymal transection. The remaining patients underwent selective vascular inflow and outflow control using the Cavitron Ultra Sonic Aspirator and Harmonic Scalpel to divide the parenchyma.

Conclusion. Care for these patients should be multidisciplinary High-volume units and access to liver transplantation offer optimal results. No technique is proven superior to the 'clamp crush' technique of parenchymal transection. Knowledge of hepatic anatomy is key to minimising morbidity, and surgeons should be familiar with and have the flexibility to use all techniques of vascular control.

S Afr Med J 2012;102(11):881-883. DOI:10.7196/SAMJ.6204
Liver resections are widely performed in paediatric surgery. Many techniques exist to achieve vascular control, minimise bleeding and complete the parenchymal division. We review our recent series of liver resections and aspects of the procedure.

\section{Methods}

Subsequent to institutional approval, a retrospective chart review was conducted of all children (aged $\leq 18$ years) who underwent a liver resection between January 2005 and June 2012 at the two teaching hospitals served by the Department of Paediatric Surgery, University of the Witwatersrand, Johannesburg. Data pertaining to basic demographics, indications for surgery, parenchymal transection techniques, morbidity, mortality and histology results were collated.

\section{Results}

During the review period, 21 liver resections were performed. Age at surgery ranged from 6 weeks to 11 years. Indications for surgery (Fig. 1) included resections for malignancy $(n=18)$, and benign disease $(n=3)$. Of the resections for malignancy, 9 were for hepatoblastomas, following cisplatinum and doxorubicin neoadjuvant chemotherapy. Type of resection per pathology (Fig. 2) included non-anatomical resections for contiguous disease in 4 patients with Wilms' tumour, and anatomical resections in the remainder. Notably, all hepatoblastomas in this series occurred in the right liver. One child died after developing acute inflow occlusion of the segment 2,3 liver remnant secondary to torsion. This was recognised immediately after leaving the operating theatre, but on re-exploration, all attempts to establish adequate sustainable inflow failed. No bile leaks or other

Department of Paediatric Surgery, Chris Hani Baragwanath Academic Hospital, Charlotte Maxeke Johannesburg Academic Hospital, University of the Witwatersrand, Johannesburg

J A Loveland, MB BCh, FCS (SA), Cert Paed Surg

F Krog, MB ChB, MRCS (Ed)

P Beale, MB BCh, FCS (SA)

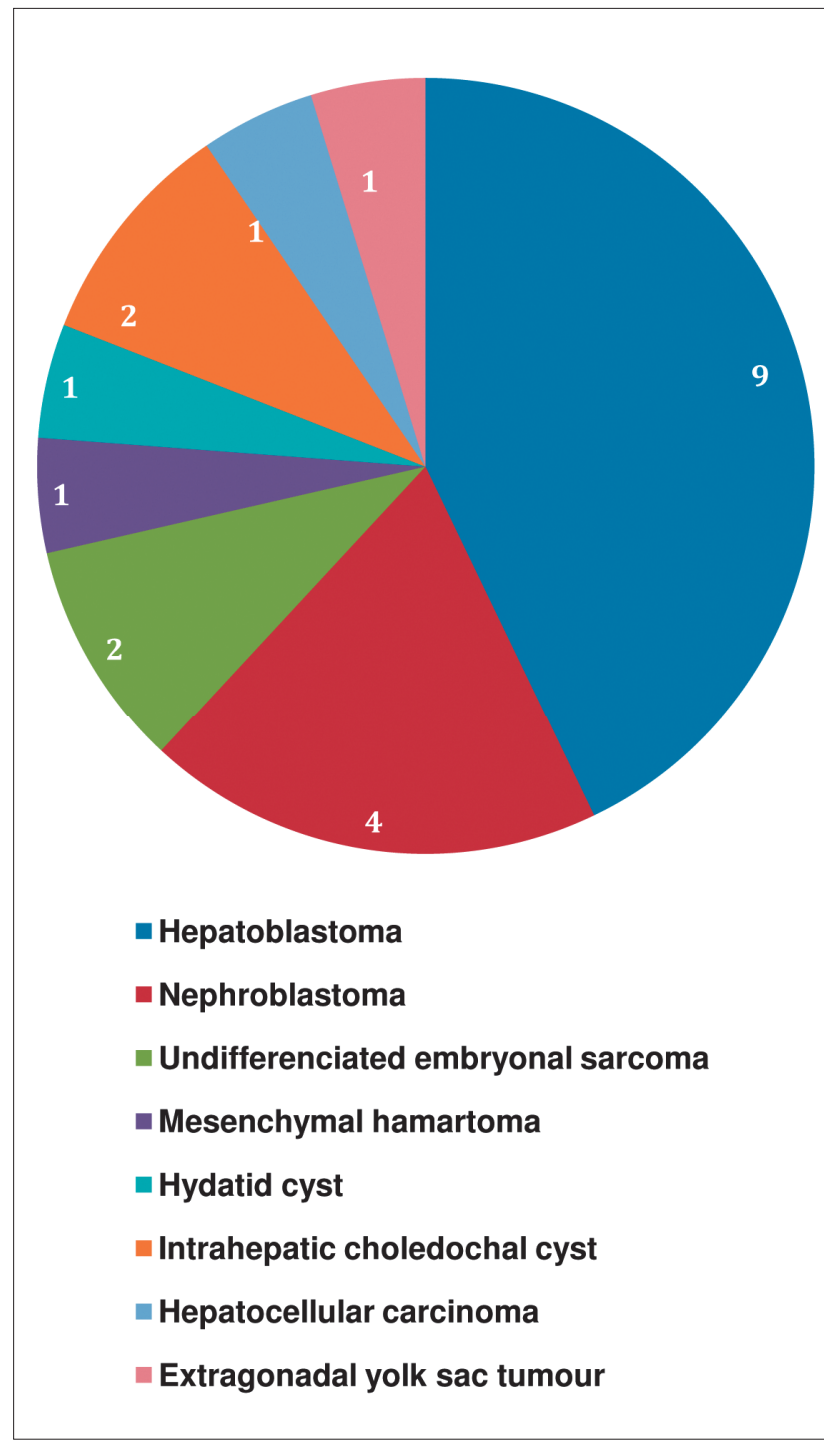

Fig. 1. Indications for surgery. 
surgical morbidities were documented in the remaining patients. With respect to resection technique, hepatic vascular exclusion (HVE) of the liver was used in 3 cases, and selective vascular inflow control combined with hepatic venous outflow control for the remainder. Parenchymal transection was performed using a surgical blade in the 3 HVE cases, with combinations of the Cavitron Ultra Sonic Aspirator (CUSA), Harmonic Scalpel, and unipolar diathermy for the rest. No patients in our series were considered for transplantation.

\section{Discussion}

The regenerative capacity of the liver was first described in ancient times, and dates back to Greek mythology: ${ }^{1}$ Prometheus, a titan and champion of mankind, stole fire from Zeus and presented it to humans. As punishment, Zeus sentenced Prometheus to eternal torment. He was incarcerated on a rock and each day an eagle was sent to feed on his liver. Fortunately (or unfortunately!) the liver regenerated each night and the eagle returned daily, sentencing Prometheus to eternal torment.

Thankfully, the regenerative capacity of the liver forms the basis of modern hepatobiliary surgery, where in the presence of a noncirrhotic liver, up to $80 \%$ of the liver can safely be resected, relying on this regenerative capacity of the remnant to sustain the patient's functional requirements. ${ }^{1}$ Liver resection progress has been significant in the last few decades and pivotal to a better understanding of liver anatomy and physiology. ${ }^{2}$

Glisson gave the first accurate insights into liver anatomy in Cambridge in 1654 when, after boiling the liver to remove the parenchyma, its vascular system was infused with coloured milk and defined. ${ }^{3}$ In 1888, Rex challenged conventional division of the liver on the basis of the falciform ligament and described an avascular plane through the liver that extended from the gallbladder fossa to the inferior vena cava (IVC) ${ }^{4}$ This was supported by Cantlie in 1897. ${ }^{5}$ Wendell and Haberer were the first surgeons to undertake anatomical resections along this line, today known as the Rex-Cantlie Line, in the beginning of the 20th century. ${ }^{6,7}$ The early masters of hepatic surgery include Langenbuch, who performed the first elective liver resection in 1888, and William Keen, who described the 'finger fracture' technique in $1891 .{ }^{8}$ To date, no technique has been demonstrated to be superior to this 'clamp crush' technique. ${ }^{9}$ In 1908, Pringle described the temporary compression of the portal triad to control the inflow of blood into the liver. ${ }^{10}$ This technique is still widely used today. The description of the intrahepatic biliary duct system and vascular tree was refined by Carl-Herman Hjortsjo. ${ }^{11}$ However, in 1954, Couinaud published his seminal work describing the segmental anatomy of the liver and dividing it into the 8 segments with which we are familiar today. ${ }^{12}$ To ensure uniform anatomical descriptions of resection, the standardised International Hepato Pancreato Biliary Association (IHPBA) Brisbane 2000 terminology of liver anatomy and resections was published, and reviewed by Strasberg in 2005. ${ }^{13,14}$

The foremost tool of the modern liver surgeon remains an indepth knowledge of the anatomy of the liver and, in particular, an awareness of the numerous deviations from normal, particularly with respect to arterial and biliary anatomy.

Concurrent with anatomical advances, anaesthesia - using ether was introduced by Crawford W Long in the 19th century, and Joseph Lister implemented antiseptic techniques in 1867 after Louis Pasteur noted the dangers of bacteria. Implementing these principles led to major advances in the quest for safe hepatic surgery. Nevertheless, in the 1950s the peri-operative mortality after a right hepatectomy approached $50 \%$. Fifty years later, Belghiti reported on 747 patients who had undergone liver resections during the 1990s with normal parynchema of the remnant, and a mortality rate of $1 \% \cdot{ }^{15}$ Cirrhosis, portal hypertension and steatosis remain the most important risk factors for mortality. ${ }^{16,17}$ Fortunately, these features are less common in the paediatric population compared with adults.

Previously thought to be a potentially 'bloody' operation, anaesthetic techniques focused on maintaining a high central venous pressure (CVP) to counteract blood loss. In reality, a 'full' IVC transmits these high pressures to the hepatic veins, actually contributing to more bleeding during the parenchymal transection. Presently, a low CVP approximating $5 \mathrm{mmHg}$ forms the cornerstone of strategies to minimise bleeding. Surgery is divided into 2 distinct phases, pre- and post-transection. Pre-transection, a low CVP should be maintained, minimal intravenous fluids administered, and vasopressors used, if necessary. Post-transection, provided that bleeding is controlled, the patient should be returned to a euvolaemic state. ${ }^{18}$

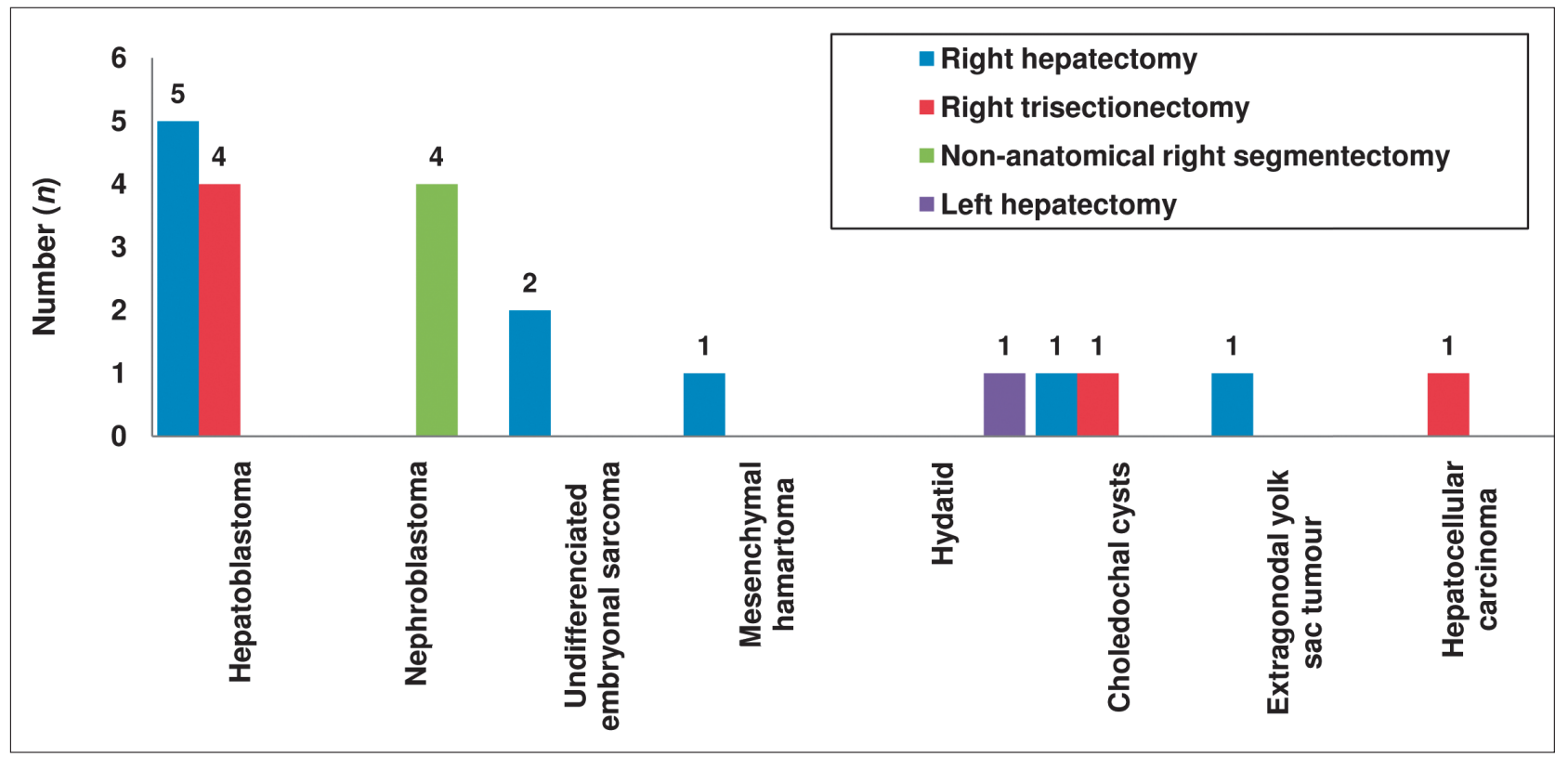

Fig. 2. Type of resection used for respective pathology. 
A multidisciplinary team approach and high-volume units confer lower morbidity rates and a survival advantage, as clearly demonstrated with the management of biliary atresia. ${ }^{19}$

Vascular control is used to minimise bleeding during the parenchymal transection. Options include the Pringle manoeuvre, various combinations of inflow and outflow control, and total hepatic isolation/HVE.

The Pringle manoeuvre, where both the common hepatic artery and portal vein are controlled in the hepatoduodenal ligament, has a minimal haemodynamic effect, although the pathological liver does not tolerate it as well as a healthy liver. In this situation, intermittent occlusion is better tolerated. In the normal liver, continuous occlusion of up to 60 minutes is acceptable and 120 minutes of intermittent occlusion is tolerated. Used in isolation, the Pringle manoeuvre does not reduce venous back-bleeding and is not our technique of choice.

Hepatic arterial and portal venous inflow to the segment(s) being resected can be isolated specifically in the porta hepatis; this is our technique of choice. Ligation of the respective hepatic artery and portal vein can be performed en masse or individually. This maintains normal inflow to the remaining liver segment, while preventing ischaemia and reducing bleeding during the parenchymal transection. This technique is combined with hepatic venous outflow control of the respective hepatic vein at its confluence with the IVC, to control back-bleeding.

Total vascular exclusion involves controlling both the supraand infrahepatic IVC, as well as temporarily occluding both the common hepatic artery and portal vein in the porta hepatis (Pringle manoeuvre). Sound knowledge of the hepatic vascular anatomy is mandatory, and it is important to control the direct venous branches between the retrohepatic IVC, the adrenal glands and segment 4 of the liver. It is also essential to perform a manual test clamp prior to formally applying clamps, as $10-15 \%$ of patients become significantly haemodynamically unstable. HVE is particularly useful in situations where the anaesthetist is unable to lower the CVP and a very high/refractory CVP persists, or where the tumour encroaches on the IVC. The procedure should not last longer than 60 minutes.

Whichever preference, the surgeon and anaesthetist must be accomplished in performing all techniques described above, and have the flexibility to use them interchangeably.

\section{Parenchymal transection}

Numerous techniques and devices have been developed to transect the hepatic parenchyma, including: 'clamp crush', vascular staplers, ultrasonic dissection, Hydrojet, tissue-sealing devices and radiofrequency-dissecting sealer. The surgeon should be familiar with the different techniques and devices and should tailor the approach to the different resections performed, as there is no modality proven to be superior in all situations. Randomised controlled studies have compared the different techniques of parenchymal transection, and concluded that there is no superior technique to 'clamp crush. ${ }^{20,21}$ The latter is based on the 'finger fracture' technique and consists of a device that crushes the parynchema, exposing the hepatic vasculature and bile ducts to allow more accurate occlusion.

\section{Role of transplantation}

Transplantation may be considered if the tumour is not macroscopically resectable, in the absence of metastatic disease. Typical indications include: tumours involving all 4 sectors of the liver, or where the residual volume is calculated to be less than $20 \%$; central tumours involving the bifurcation of the main portal vein; significant involvement of the IVC; and recurrent disease after previous resection. Results of primary transplantation are far better than salvage transplantation for recurrent disease after primary resection.

\section{Conclusion}

There is no doubt that caring for these patients in a multidisciplinary environment is optimal. High-volume units offer the best results and treating these patients in a surgical unit with access to liver transplantation offers a complete solution for all manners of presentation. An indepth knowledge of hepatic anatomy remains key to successful outcomes with minimal morbidity. While our unit prefers to isolate both the inflow and outflow to a specific segment of liver, surgeons should have the flexibility to use all techniques. Total hepatic isolation is recommended where the tumour is adjacent to or involves the IVC, or nestles in close proximity to the left or right portal veins.

\section{References}

1. Taub R. Liver regeneration: from myth to mechanism. Nat Rev Mol Cell boil 2004;5:836-847. [http:// dx.doi.org/10.1038/nrml489]

2. Lehmann K, Clavien P. History of hepatic surgery. Surg Clin North Am 2010;90(4):655-664. [http://dx.do org/10.1016/j.suc.2010.04.018

3. GlissonF.Anatomiahepatis London:Dugard, 1654. [http://dx.doi.org/10.1001/jama.1963.03700200106024] 4. Rex H. Beitrage zur morphologie der saugerleber. Morphol Jahrb 1888;14:517. [http://dx.dol org/10.1001/archsurg.2012.689

5. Cantlie J. On a new arrangement of the right and left lobes of the liver. Proceedings - Anatomical Society of Great Britian and Ireland 1897:32:4-9. [http://dx.doi.org/10.1111/j.1477-2574.2009.00124.x] 6endell W. Beitrage zur chirurgie der leber. Arch Klin Chir 1911:95:887.

7. von Haberer H. Zur frage der nicht parasitaren leber. Wien Klin Wochenschr 1909:22:1788.

8. Langenbuch C. Ein fall von resection eines linksseitigen schnurlappens der leber. Heilung Klin Wochenschr 1888;25:37.

9. Heriot AG, Karanjia ND. A review of techniques for liver resection. Ann R Coll Surg Eng 2002;84(6):371-380. [http://dx.doi.org/10.1308/003588402760978148]

10. Pringle JH. Notes on the arrest of hepatic hemorrhage due to trauma. Ann Surg 1908:48(4):541-549.

11. Hiortsjo $\mathrm{CH}$. The topography of the intrahepatic duct system. Acta Anat 1951;11(4):599-615, [http:/ dx.doi.org/10.1159/000140534

dx.doi.org/10.1159/000140534] Presse Med 1954;62(33):709-712.

13. The Terminology Committee of the IHPBA. The Brisbane 2000 terminology of hepatic anatomy and resections. HPB 2000;2:333-339. [http://dx.doi.org/10.1080/136518202760378489]

14. Strasberg SM. Nomenclature of hepatic anatomy and resections: a review of the Brisbane 2000 system. .

Jepatobiliary Pancreat Surg 2005;12(5).351-355. [http://dx.doi.org/10.1007/s00534-005-0999-7] . Belghit J, Hiramatsu K, Benoist S, et al. Seven hundred forty-seven hepatectomies in the 1990s: ;191(1):38-46. [http://dx.doi

16. Nagasue N, Yukaya H, Ogawa Y, et al. Human liver regeneration after major hepatic resection. A study of normal liver and livers with chronic hepatitis and cirrhosis. Ann Surg 1987;206(1):30-39.

17. McCormack L, Petrowsky H, Jochum W, et al. Hepatic steatosis is a risk factor for postoperative McCormack L, Petrowsky H, Jochum W, et al. Hepatic steatosis is a risk factor for postoperative
complications after major hepatectomy: a matched case-control study Ann Surg 2007:245(6):923-930. [http://dx.doi.org/10.1097/01.sla.0000251747.80025.b7]

18. Rees $M$, Plant $G$, Wells 5 et al. One hundred and fifty hepatic resections. evolution of technique towards bloodless surgery. Br J Surg 1996;83(11):1526-1529.

. [http://dx.doi.org/10.1053/..sempedsurg. 2008.02.007]

20. Lesurtel M, Selzner M, Petrowsky H, et al. How should transection of the liver be performed? A prospective randomized study in 100 consecutive patients: comparing four different transection strategies. Ann Surg 2005;242(6);814-822.

1. Storck BH, Rutgers EJ, Gortzak E, Zoetmulder FA. The impact of the CUSA ultrasonic dissection device on major liver resections. Neth J Surg 1991;43(4):99-101. 